\title{
Factors influencing warfarin control in Australia and Singapore
}

Nijole Bernaitis ${ }^{\mathrm{a}, \mathrm{b}}$, Ching Chi Keong ${ }^{\mathrm{c}}$, Teo Siew Chong ${ }^{\mathrm{d}}$, Chen Liping ${ }^{\mathrm{d}}$, Tony Badrick ${ }^{\mathrm{e}}$, Andrew K

Davey $^{\mathrm{a}, \mathrm{b}}$, Julia Crilly ${ }^{\mathrm{a}, \mathrm{f}}$, Shailendra Anoopkumar-Dukie ${ }^{\mathrm{a}, \mathrm{b}^{*}}$

${ }^{a}$ Menzies Health Institute and Quality Use of Medicines Network, Queensland, Griffith University, Queensland, Australia

${ }^{\mathrm{b}}$ School of Pharmacy, Griffith University, Queensland, Australia

${ }^{\mathrm{c}}$ Cardiology Department, National Heart Centre Singapore, Singapore

${ }^{\mathrm{d}}$ Pharmacy Department, National Heart Centre Singapore, Singapore

${ }^{\mathrm{e}}$ RCPA Quality Assurance Programs, New South Wales, Australia

${ }^{f}$ Department of Emergency Medicine Gold Coast Health, Queensland, Australia

*Corresponding author.

Dr Shailendra Dukie

Tel.: +610755527725

Fax: +61 0755528804

E-mail address: s.dukie@griffith.edu.au

Postal address: School of Pharmacy, Gold Coast Campus, Griffith University, QLD 4222, Australia

Word Count : 6445 


\section{ABSTRACT}

\section{INTRODUCTION}

Warfarin is widely used for patients with non-valvular atrial fibrillation (NVAF). Variations in warfarin control, as measured by time in therapeutic range (TTR), have been reported across different regions and ethnicities, particularly between Western and Asian countries. However there is limited data on comparative factors influencing warfarin control in Caucasian and Asian patients. Therefore, the aim of this study was to determine warfarin control and potential factors influencing this in patients with NVAF in Australia and Singapore.

\section{METHODS}

Retrospective data was collected for patients receiving warfarin for January to June 2014 in Australia and Singapore. TTR was calculated for individuals with mean patient TTR used for analysis. Possible influential factors on TTR were analysed including age, gender, concurrent co-morbidities, and concurrent medication.

\section{RESULTS}

The mean TTR was significantly higher in Australia (82\%) than Singapore (58\%). At both sites, chronic kidney disease significantly lowered this TTR. Further factors influencing control were anaemia and age $<60$ years in Australia, and vascular disease, $\mathrm{CHA}_{2} \mathrm{DS}_{2}$-VASc score of 6 , and concurrent platelet inhibitor therapy in Singapore.

\section{DISCUSSION}

Warfarin control was significantly higher in Australia compared to Singapore, however chronic kidney disease reduced control at both sites. The different levels of control in these two countries, together with patient factors further reducing control may impact on anticoagulant choice in these countries with better outcomes from warfarin in Australia compared to Singapore. 
Key words: warfarin, atrial fibrillation, international normalised ratio 


\section{INTRODUCTION}

Warfarin is widely used to prevent embolic stroke in patients with atrial fibrillation(AF).(1) The anticoagulant activity of warfarin is influenced by a number of genetic and environmental factors leading to large inter-individual and inter-ethnic differences in warfarin response.(2) This variability in response necessitates close monitoring of warfarin using the International normalised Ratio(INR).(3) Maintaining a patient within therapeutic INR range is associated with improved outcomes and time in therapeutic range(TTR) may be used to assess the quality of warfarin management.(4) Increasing the TTR can improve the safety and efficacy of warfarin, with target goals of $70 \%$ suggested to enhance patient outcomes.(5) However, Mearns et al(6) reported AF patients worldwide spend only $61 \%$ TTR but found differences reported between practice settings and according to geographical region. Similarly, Baker et al(7) reported only 55\% TTR in patients with AF but, further to this, found only about $48 \%$ of patients with AF eligible for anticoagulation actually receive warfarin. Concerns regarding under treatment and ineffective management with warfarin have led to the development of new oral anticoagulants(NOACs).(8)

Comparative trials of warfarin to the NOACs in patients with non-valvular AF (NVAF) have demonstrated the NOACs to be non-inferior(9) or slightly superior(10) to warfarin in terms of stroke and systemic embolism, and associated with lower intracranial haemorrhage rates. $(9,10)$ However, Gomez-Outes et al(9) demonstrated differences in outcomes according to warfarin TTR and suggested a trend towards superiority of the NOACs in centres with TTR $<65 \%$. Subsequent subanalyses have demonstrated large variations in warfarin TTR according to geographical region with the highest in Western Europe $(11,12)$ and lowest in India(11) and East Asia(12). Similar to this, Chiang et al(13) demonstrated consistently lower TTRs in Asians compared to non-Asians, and suggested difficulty in optimising warfarin use led to potential benefits of NOACs in Asian populations. 
Amerena et al(14) found significant regional differences in treatment strategies and clinical cardiovascular outcomes in AF patients across Asia-Pacific countries. Chen et al(15) reported more than $70 \%$ of physicians in Australia and Singapore prescribe oral anticoagulants for stroke prevention but found suboptimal warfarin control to be a larger problem in Asia than other regions. Subanalyses of the large comparative trials have demonstrated warfarin control of around 75\% TTR in Australia and 65\% TTR in Singapore.(12, 16) Outside of these trials, the limited data on warfarin control in these countries have reported similar results with TTRs between $55 \%(17)$ and $81 \%(18)$ in Australia, and between $58 \%(19)$ and $65 \%(20)$ in Singapore. Wang et al(21) suggested the differential effects in warfarin control seen between Asians and non-Asians may be influenced by genetic polymorphisms, but also affected by demographic differences including body weight and renal function. However, to our knowledge, there are no real-world studies comparing the influence of clinical characteristics on warfarin control in both Caucasian and Asian populations. Therefore, the aim of this study was to determine the level of warfarin control in patients with NVAF in Australia and Singapore and identify potential factors influencing this control including demographic and clinical characteristics.

\section{METHODS}

Ethics approval was obtained from Griffith University (PHM/09/14/HREC and PHM/08/15/HREC) and SingHealth Centralised Institutional Review Board (CIRB 2015/2435). Retrospective data was collected for patients receiving warfarin for AF for the period of January 2014 to June 2014 in Australia and Singapore. The Australian site was Sullivan Nicolaides Pathology, Queensland, and included patients enrolled in their warfarin management program. The Singapore site was The National Heart Centre Singapore, and included patients seen at the outpatient warfarin clinic and dispensed warfarin. To identify patients with NVAF, patients with mitral stenosis, valve replacement and/or valve repair were excluded from the study. Data collected included age, gender, comorbidities, concurrent medications, warfarin dose and dose changes during the study period. 
Further information included INR test date and result, and target range. Individual TTR was calculated using Rosendaal's linear interpolation algorithm (22) with software downloaded from INR Pro@. Patient exclusions were insufficient tests to calculate TTR (ie less than 2 tests) and a time of treatment of less than 30 days.

Statistical analysis was performed using GraphPad Instat Version 3 with patient characteristics reported as number and percentage for categorical data, mean \pm standard deviation for continuous data, and median and interquartile ranges for risk scores and warfarin doses. Mean data was used for analysis and comparison between sites for warfarin control and doses. Mean TTR was used to identify possible influential factors on TTR at each site including age, gender, concurrent comorbidities, and concurrent medication. Patients with specific factors present (e.g.hypertension) were identified and the mean TTR of this group compared to the mean TTR for the site. Patients at each site were also categorised according to TTR above or below $65 \%$ for comparison within that site. Comparisons were made using ordinary analysis of variance through non-parametric methods, including Mann-Whitney test for univariate analysis and Dunn's multiple comparisons test for bivariate analysis. Significance was defined as ${ }^{*} p<0.05,{ }^{* *} p<0.01$, and ${ }^{* * *} p<0.001$, and graphing performed with GraphPad Prism 6.

\section{RESULTS}

Of the 5554 patients being treated with warfarin for NVAF, a total of 4366 were included in the study. There were 3196 patients at the Australian site following exclusions for valvular AF (276), insufficient tests to calculate TTR (4), treatment time of less than 30 days (40), and incomplete warfarin dose information (3), and there were 1170 patients at the Singapore site following these exclusions (605, 195, 64 and 1 patient respectively). The majority of patients were male comprising $52.3 \%$ of patients in Australia and $60.3 \%$ in Singapore(Table 1 ). Mean age of patients was $77.2 \pm 9.1$ years in Australia and $69.7 \pm 10.0$ years in Singapore which was statistically different $(p<0.0001)$. The 
most common medical condition at both sites was hypertension (37.0\% Australia, 59.6\% Singapore). The prevalence of other co-morbidities differed but diabetes (17.6\% Australia, 30.0\% Singapore), dyslipidaemia (14.7\% Australia, 51.9\% Singapore), and vascular disease (11.2\% Australia, 23.8\% Singapore) were amongst the most common. Both sites had a median $\mathrm{CHA}_{2} \mathrm{DS}_{2}-\mathrm{VASc}$ score of 3 and a median HASBLED score of 1 at the start of the study period. Concurrent treatment with betablockers was most common at both sites (62.4\% Australia, 77.9\% Singapore), followed by statins (55.2\% Australia, $72.8 \%$ Singapore).

$<$ Insert Table 1>

During the study period there were a total of 35898 INR tests in Australia and 6588 in Singapore (Table 2). The mean TTR was $82.3 \pm 15.6 \%$ in Australia and $57.6 \pm 34.2 \%$ in Singapore which was statistically different $(p<0.0001)$. The mean percentage of tests in range was statistically different between Australia and Singapore $(78.9 \pm 19.1 \%$ versus $54.2 \pm 30.5 \%, p<0.0001)$ as was the mean time between testing $(16.9 \pm 8.1$ versus $29.3 \pm 15.2$ days, $p<0.0001)$. The median weekly warfarin dose was $24.3 \mathrm{mg}$ (IQR 3.5-94.5) in Australia and $16.5 \mathrm{mg}$ (IQR 3.5-63) in Singapore, with a median of 2 (IQR 018) dose changes in Australia and 0 (IQR 0-9) in Singapore.

$<$ Insert Table 2>

Comparison of patients according to TTR less than or greater than $65 \%$, found a TTR $>65 \%$ in $86 \%$ of patients in Australia and $46 \%$ of patients in Singapore (Table 3). There was a significantly reduced frequency of testing and number of dose changes in the patients with TTR $>65 \%$ in both Australia and Singapore.

$<$ Insert Table 3>

Univariate analysis of the mean TTR at each site to demographic and clinical factors found significant differences with three factors in Australia and four factors in Singapore(Figure 1). Chronic kidney disease was associated with a statistically lower TTR in Australia $(77.2 \pm 16.8 \%, p=0.002)$ and 
Singapore $(50.9 \pm 32.9 \%, p=0.0165)$. In Australia, anaemia and age less than 60 years were associated with significantly lower TTR. In Singapore, vascular disease, $\mathrm{CHA}_{2} \mathrm{DS}_{2}-\mathrm{VASc}$ score of 6 , and concurrent platelet inhibitor therapy were associated with significantly lower TTR.

$<$ Insert Figure $1>$

\section{DISCUSSION}

Warfarin has been used for decades in patients with AF but suboptimal use can lead to poor patient outcomes.(23) Alternative anticoagulants are now available for patients with NVAF, but the comparative benefits of these agents over warfarin appears dependent on the quality of warfarin control.(9) Regional differences in warfarin control have been reported with higher TTRs in Western countries and lower TTRs in Asian countries.(12) Suboptimal control in Asians has been suggested to be due to genetic polymorphisms and demographic differences(21), with the ethnic differences in risk profiles favouring NOACs in Asian patients with AF. However, despite the fact that the selection of warfarin or a NOAC appears dependent on TTR and influenced by patient factors(24), there is limited data on comparative factors influencing warfarin control in Caucasian and Asian patients. Therefore, the aim of this study was to determine warfarin control and potential factors influencing this in patients with NVAF in Australia and Singapore. This study found significant differences between Australia and Singapore in the mean warfarin TTR ( $82 \%$ and $58 \%$ respectively) and frequency of testing (17 and 29 days respectively). A higher proportion of patients in Australia achieved a TTR $>65 \%$ compared to Singapore ( $86.0 \%$ and $46.4 \%$ respectively). In both Australia and Singapore, a lower TTR was associated with chronic kidney disease. Other factors influencing TTR were anaemia and age $<60$ years in Australia, and vascular disease, $\mathrm{CHA}_{2} \mathrm{DS}_{2}$-VASc score of 6 , and concurrent platelet inhibitor therapy in Singapore.

AF is the most common sustained cardiac arrhythmia with a higher prevalence in men and an incidence that increases with age.(25) Chiang et al(26) found patients in the Asia-Pacific region to 
have similar disease profiles to those in the rest of the world, with hypertension the most prevalent risk factor but a higher prevalence of valvular heart disease in Asia.(26) Consistent with this, in both Australia and Singapore, our study included a higher percentage of males and hypertension was the most common co-morbidity. The most common concurrent treatment at both sites was with betablockers which is also consistent with Amerena et al(14) who concluded that clinicians in the AsiaPacific region prefer rate-control strategies. However there were several differences between the two populations. Consistent with Hori et al(27), the mean age of patients with AF in our Asian population was younger. Similarly, as described by Frank et al (28), there were higher rates of dyslipidaemia and vascular disease in our Asian population. Higher rates of statin and platelet inhibitors were also seen in our Asian population. Chen et al (15) reported higher proportions of Asian patients on antiplatelet therapy and, further to this, revealed overuse of anticoagulant therapy in low risk $\left(\mathrm{CHA}_{2} \mathrm{DS}_{2}-\mathrm{VASC}=0\right)$ patients in many countries. Similar to this, our warfarin study included patients with $\mathrm{CHA}_{2} \mathrm{DS}_{2}$-VASc scores of 0 however further investigation is required to determine the rationale for warfarin therapy in these patients.

Suarez et al(29) found vast differences in anticoagulant use in the Asia Pacific region with Australia having the highest adjusted rate of warfarin use. Australia had amongst the highest warfarin control in sub-analyses of the large comparative trials of warfarin to the NOACs with almost $75 \%$ TTR, whilst the TTR in Singapore was around 65\%.(12,16) Real-world data of warfarin control in patients with AF reported similar results with a TTR of $81 \%$ in Australia(18) and $58 \%$ in Singapore(19). Our study reported similar TTRs in Australia (82\%) and Singapore (58\%) and found a TTR>65\% in $86 \%$ of Australian patients but only $46 \%$ of patients in Singapore. Further to this, our study found significant differences between these countries in frequency of testing and dose changes but also significant differences in these parameters for patients with TTR above and below $65 \%$ at both sites. The testing interval of 17 days in Australia and 29 days in Singapore was similar to results from Oh et al(30) who reported a median interval of testing of 14 days in other world regions compared to 28 days in Asia. Carrier et al(31) concluded that patients with 9 or more INR tests and 3 or more dose 
changes in a six month period were more likely to have a $T T R<65 \%$. In contrast, our Australian population with an average of 10 tests and a mean 2.5 dose changes in the six month study had a high TTR of $82 \%$. However, in the Australian patients with a TTR $<65 \%$, the number of INR tests in the six month period was a higher 16 and they had 6 dose changes. Similar to this result, Schaefer et al(32) associated poor control with long intervals between tests defining this as an interval $>14$ days. However, in our Singapore population with a TTR<65\% the testing interval was 24 days. Ansell et al(33) reported a median monitoring interval of 20-21 days across five countries but reported that structured clinics achieve greater TTR due to differences in the frequency of consultations and response to non-therapeutic INRs. Previously, Lip et al(34) suggested the poorer TTRs in Asians may be attributed to the lack of structured anticoagulation services. Chua et al(20) describe improved outcomes with anticoagulation clinics in Singapore but note that the increased frequency of consultations can substantially increase a patient's out-of-pocket expenses. Whilst the more frequent testing in Australia resulted in significantly better control than Singapore, in both these populations, patients with poor control as defined by TTR<65\% had more frequent testing suggesting simply testing more frequently cannot improve control. Therefore, further investigation is needed to determine the most suitable interval of testing and the optimal follow-up of out of range INRs to maintain cost-effectiveness and achieve high warfarin TTR.

No significant influence between TTR and warfarin dose was found in either Australia or Singapore. Previously, poorer warfarin control has been associated with higher warfarin doses by Okumura et al(35) and, in contrast, with lower doses by Palaretti et al(36). There were significant differences in the weekly warfarin doses in Australia and Singapore (26 mg and $18 \mathrm{mg}$ respectively). Jonas et al(38) suggested that whilst age, race, and medications all influence dose requirements, it is genetic polymorphisms in enzymes important in warfarin pharmacology that account for about $40 \%$ of warfarin dose variations. Further to this, Dang et al(39) found that when adjusted for confounding factors, warfarin dose requirements varied across ethnic groups with Asians requiring lower doses than Caucasians. Consistent with Dang et al(39) we found higher doses in Australia compared to 
Singapore, although the mean weekly doses in their study of $36 \mathrm{mg}$ for Caucasians and $24 \mathrm{mg}$ for Asians were higher than our study ( $26 \mathrm{mg}$ and $18 \mathrm{mg}$ respectively). Further investigation is needed to determine if further adjustment in warfarin dose could result in improvement of TTR, particularly if guided by dosing algorithms incorporating both genetic and clinical factors.

The clinical factor associated with significantly decreased TTR in both Australia and Singapore was chronic kidney disease. Previous studies(40-42) have also associated chronic kidney disease with worse INR control and substantially lower TTR. Poorer control has been associated with moderate to severe kidney disease(43) with a proposed mechanism being altered warfarin disposition due to reduced hepatic cytochrome metabolism from cytokines and uremic toxins.(44) Pokorney et al(45) found patients with renal dysfunction had lower median TTRs, but also associated younger age and a high $\mathrm{CHA}_{2} \mathrm{DS}_{2}$-VASc score of $\geq 5$ with decreased TTR. Similar to this, we found age less than 60 to be associated with decreased TTR in Australia and a $\mathrm{CHA}_{2} \mathrm{DS}_{2}$-VASc score of 6 associated with decreased TTR in Singapore. In contrast, Putnam et al(46) found no correlation with warfarin control and $\mathrm{CHADS}_{2}$ score, whilst Gallagher et al(47) found no substantial variation in TTR according $\mathrm{CHA}_{2} \mathrm{DS}_{2}-$ VASc score or age. In our study, age was only associated with poor control in Australia and not Singapore, with a reduced TTR in patients $<60$ years plus a younger age was found in patients with a TTR<65\%. Interestingly, age has been found to have variable effects on TTR with reports of no influence on TTR(48), TTR increasing with age(49), and poorer anticoagulation control associated with younger age as defined by $<45$ years $(50)$ or $<60$ years(51). In addition to age, Dlott et al(50) and Apostolakis et al(51) associated female gender to influence warfarin control. In contrast to these authors, we found gender did not influence TTR in either Australia or Singapore. This finding corresponds to those of Gallagher et al(47) and Okumura et al(35) who also demonstrated no gender influences on TTR.

Further influences on TTR in our study included anaemia in Australia and vascular disease in Singapore. Lip et al(52) reported haemoglobin $\leq 13.5 \mathrm{~g} / \mathrm{dl}$ to be associated with lower mean TTR and, 
whilst they did not find an association with TTR and coronary artery disease or peripheral artery disease, these authors suggested warfarin control is related to a patients overall clinical status. Further to this, Apostalakis et al(51) associated multiple co-morbidities with poorer warfarin control and also demonstrated the influence of interacting drugs such as amiodarone. Although our study did not investigate the influence of multiple co-morbidities on TTR, we found amiodarone both alone and in combination with beta-blockers did not influence warfarin control. This may be due to the well-documented interaction between warfarin and amiodarone and awareness by clinicians regarding potential influences on warfarin TTR. In the same way, the majority of medications were found to have no effect on warfarin control, with the exception of platelet inhibitors in Singapore. This is in contrast to Okumura et al(35) who found no differences in TTR with co-administration of anti-platelet agents and Mueller et al(48) who found no differences in TTR and concurrent aspirin therapy. However, concomitant use of warfarin and drugs with pharmacodynamic interactions do not usually result in INR changes but may increase the risk of bleeding.(53) Guo et al (54) describe higher risks of major bleeding and intracranial haemorrhage in Asian patients with AF. Thus, the reduced TTR with anti-platelets only seen in the Singapore population may reflect concerns regarding bleeding in this population. The retrospective nature of the study limits the ability to test this and other hypotheses, so further prospective studies would be required for conclusions to be made.

Patient demographics, co-morbidities, plus stroke and bleed risk are all strong determining factors in a patient's suitability for anticoagulant therapy.(60) In global studies of warfarin, Singer et al(12) concluded that patient clinical factors were modest determinants of TTR but the strongest determinants was geographic region and medical care practices. This study found significant differences in terms of warfarin control between Australia and Singapore (TTR $82 \%$ and 58\% respectively). This is consistent with previous findings suggesting suboptimal warfarin control is a bigger problem in Asia than other regions. $(15,61)$ There are now alternate anticoagulant options to warfarin and the benefit of these NOACs over warfarin has been demonstrated in centres with 
TTR $<65 \%$.(9) The percentage of patients with a TTR $>65 \%$ was $86 \%$ in Australia and $46 \%$ in Singapore. Based on these results and the mean TTR at our two study sites, for the majority of patients, warfarin would remain favourable in Australia whilst the NOACs would be preferred in Singapore. Complicating this recommendation is the fact that chronic kidney disease significantly decreased TTR at both sites. Renal impairment impacts dosing and safety of the NOACs(62) and thus this population of patients with NVAF present a particular challenge.

In conclusion, this study in patients with NVAF found a high level of warfarin control in Australia with a TTR of $82 \%$, but poorer control of $58 \%$ in a Singapore population. Patient factors influencing this control were chronic kidney disease at both sites, in addition to anaemia and age $<60$ years in Australia, and vascular disease, $\mathrm{CHA}_{2} \mathrm{DS}_{2}$-VASc score of 6 , and concurrent platelet inhibitor therapy in Singapore. These influences on warfarin control, together with the differing levels of control seen across the Asia-Pacific region, may impact on anticoagulant choice in these countries with better outcomes from warfarin in Australia compared to Singapore.

Funding: This research did not receive any specific grant from funding agencies in the public, commercial, or not-for-profit sectors. 


\section{REFERENCES}

1. Pirmohamed M. Warfarin: almost 60 years old and still causing problems. British journal of clinical pharmacology. 2006;62(5):509-11.

2. D'Andrea G, D'Ambrosio R, Margaglione M. Oral anticoagulants: Pharmacogenetics: Relationship between genetic and non-genetic factors. Blood reviews. 2008;22(3):127-40.

3. Hirsh J, Poller L. The international normalized ratio: a guide to understanding and correcting its problems. Archives of internal medicine. 1994;154(3):282-8.

4. Schmitt L, Speckman J, Ansell J. Quality assessment of anticoagulation dose management: comparative evaluation of measures of time-in-therapeutic range. Journal of thrombosis and thrombolysis. 2003;15(3):213-6.

5. Rose AJ, Hylek EM, Ozonoff A, Ash AS, Reisman JI, Berlowitz DR. Risk-adjusted percent time in therapeutic range as a quality indicator for outpatient oral anticoagulation results of the Veterans Affairs Study To Improve Anticoagulation (VARIA). Circulation: Cardiovascular Quality and Outcomes. 2011;4(1):22-9.

6. Mearns ES, White CM, Kohn CG, Hawthorne J, Song J-S, Meng J, et al. Quality of vitamin K antagonist control and outcomes in atrial fibrillation patients: a meta-analysis and meta-regression. Thrombosis Journal. 2014;24(12):14.

7. Baker WL, Cios DA, Sander SD, Coleman Cl. Meta-analysis to assess the quality of warfarin control in atrial fibrillation patients in the United States. Journal of Managed Care Pharmacy. 2009;15(3):244-52.

8. Bhusri S, Ansell J. New anticoagulants in atrial fibrillation: an update for clinicians. Therapeutic advances in chronic disease. 2012;3(1):37-45.

9. Gomez-Outes A, Terleira-Fernandez Al, Calvo-Rojas G, Suarez-Gea ML, Vargas-Castrillon E. Dabigatran, Rivaroxaban, or Apixaban versus Warfarin in Patients with Nonvalvular Atrial Fibrillation: A Systematic Review and Meta-Analysis of Subgroups. Thrombosis. 2013;2013:18.

10. Miller CS, Grandi SM, Shimony A, Filion KB, Eisenberg MJ. Meta-analysis of efficacy and safety of new oral anticoagulants (dabigatran, rivaroxaban, apixaban) versus warfarin in patients with atrial fibrillation. The American journal of cardiology. 2012;110(3):453-60.

11. Wallentin L, Lopes RD, Hanna M, Thomas L, Hellkamp A, Nepal S, et al. Efficacy and safety of apixaban compared with warfarin at different levels of predicted INR control for stroke prevention in atrial fibrillation. Circulation. 2013;127(22):2166-76.

12. Singer DE, Hellkamp AS, Piccini JP, Mahaffey KW, Lokhnygina Y, Pan G, et al. Impact of global geographic region on time in therapeutic range on warfarin anticoagulant therapy: data from the ROCKET AF clinical trial. Journal of the American Heart Association. 2013;2(1):e000067.

13. Chiang C-E, Wang K-L, Lip G. Stroke prevention in atrial fibrillation: an Asian perspective. Thrombosis and Haemostasis. 2014;111(5):789-97.

14. Amerena J, Chen S-A, Sriratanasathavorn C, Cho J-G, Dejia H, Omar R, et al. An International Observational Prospective Survey Assessing the Control of Atrial Fibrillation in Asia-Pacific: Results of the Record-AFAP Registry. Clinical Medicine Insights Cardiology. 2015;9:77.

15. Chen $\mathrm{C}-\mathrm{H}$, Chen M-C, Gibbs H, Kwon SU, Lo S, On YK, et al. Antithrombotic treatment for stroke prevention in atrial fibrillation: The Asian agenda. International journal of cardiology. 2015;191:244-53.

16. Wallentin L, Yusuf S, Ezekowitz MD, Alings M, Flather M, Franzosi MG, et al. Efficacy and safety of dabigatran compared with warfarin at different levels of international normalised ratio control for stroke prevention in atrial fibrillation: an analysis of the RE-LY trial. The Lancet. 2010;376(9745):975-83.

17. Dennis J, Majoni W, Tinsley J, Kangaharan N. Safety and Efficacy of Warfarin Therapy in Remote Communities of the Top End of Northern Australia. Heart, Lung and Circulation. 2017.

18. Bernaitis N, Badrick T, Davey AK, Anoopkumar-Dukie S. Quality of warfarin control in atrial fibrillation patients in South East Queensland, Australia. Internal medicine journal. 2016;46(8):92531. 
19. Bernaitis N, Ching CK, Chen L, Hon JS, Teo SC, Davey AK, et al. The Sex, Age, Medical History, Treatment, Tobacco Use, Race Risk (SAMe TT 2 R 2) Score Predicts Warfarin Control in a Singaporean Population. Journal of Stroke and Cerebrovascular Diseases. 2017;26(1):64-9.

20. Chua WBB, Cheen HHM, Kong MC, Chen LL, Wee HL. Modelling the cost-effectiveness of pharmacist-managed anticoagulation service for older adults with atrial fibrillation in Singapore. International journal of clinical pharmacy. 2016;38(5):1230-40.

21. Wang K-L, Lip GY, Lin S-J, Chiang C-E. Non-Vitamin K Antagonist Oral Anticoagulants for Stroke Prevention in Asian Patients With Nonvalvular Atrial Fibrillation Meta-Analysis. Stroke. 2015;46(9):2555-61.

22. Rosendaal F, Cannegieter S, Van der Meer F, Briet E. A method to determine the optimal intensity of oral anticoagulant therapy. Thrombosis and haemostasis. 1993;69(3):236-9.

23. Amin A, Lingohr-Smith M, Bruno A, Trocio J, Lin J. Economic evaluations of medical cost differences: use of targeted-specific oral anticoagulants vs. warfarin among patients with nonvalvular atrial fibrillation and venous thromboembolism in the US. Journal of Hematology \& Thromboembolic Diseases. 2015;2015.

24. Coyle D, Coyle K, Cameron C, Lee K, Kelly S, Steiner S, et al. Cost-effectiveness of new oral anticoagulants compared with warfarin in preventing stroke and other cardiovascular events in patients with atrial fibrillation. Value in health. 2013;16(4):498-506.

25. Ball J, Carrington MJ, McMurray JJ, Stewart S. Atrial fibrillation: profile and burden of an evolving epidemic in the 21st century. International journal of cardiology. 2013;167(5):1807-24.

26. Chiang C-E, Zhang S, Tse HF, Teo WS, Omar R, Sriratanasathavorn C. Atrial fibrillation management in Asia: from the Asian expert forum on atrial fibrillation. International journal of cardiology. 2013;164(1):21-32.

27. Hori M, Connolly SJ, Zhu J, Liu LS, Lau C-P, Pais P, et al. Dabigatran Versus Warfarin. Effects on Ischemic and Hemorrhagic Strokes and Bleeding in Asians and Non-Asians With Atrial Fibrillation. 2013;44(7):1891-6.

28. Frank AT, Zhao B, Jose PO, Azar KM, Fortmann SP, Palaniappan LP. Racial/ethnic differences in dyslipidemia patterns. Circulation. 2013:CIRCULATIONAHA. 113.005757.

29. Suarez J, Piccini JP, Liang L, Atherton JJ, Hayward CS, Krum H, et al. International variation in use of oral anticoagulation among heart failure patients with atrial fibrillation. American heart journal. 2012;163(5):804-11.

30. Oh S, Goto S, Accetta G, Angchaisuksiri P, Camm AJ, Cools F, et al. Vitamin K antagonist control in patients with atrial fibrillation in Asia compared with other regions of the world: Realworld data from the GARFIELD-AF registry. International Journal of Cardiology. 2016;223:543-7.

31. Carrier M, Kimpton M, Wells PS, Langlois N, Kherani S, Le Gal G. A simple method to identify patients on long-term warfarin who may derive the most benefit from new oral anticoagulants. Blood Coagulation \& Fibrinolysis. 2014;25(8):812-5.

32. Schaefer C, Wuillemin WA, Kessels A, Jacobson A, Nagler M. Predictors of anticoagulation quality in 15834 patients performing patient self-management of oral anticoagulation with vitamin $\mathrm{K}$ antagonists in real-life practice: a survey of the International Self-Monitoring Association of Orally Anticoagulated Patients. British Journal of Haematology. 2016;175(4):677-85.

33. Ansell J, Hollowell J, Pengo V, Martinez-Brotons F, Caro J, Drouet L. Descriptive analysis of the process and quality of oral anticoagulation management in real-life practice in patients with chronic non-valvular atrial fibrillation: the international study of anticoagulation management (ISAM). Journal of thrombosis and thrombolysis. 2007;23(2):83-91.

34. Lip GY, Wang K-L, Chiang C-E. Non-vitamin K antagonist oral anticoagulants (NOACs) for stroke prevention in Asian patients with atrial fibrillation: time for a reappraisal. International journal of cardiology. 2015;180:246-54.

35. Okumura K, Komatsu T, Yamashita T, Okuyama Y, Harada M, Konta Y, et al. Time in the Therapeutic Range During Warfarin Therapy in Japanese Patients With Non-Valvular Atrial 
Fibrillation-A Multicenter Study of Its Status and Influential Factors. Circulation Journal. 2011;75(9):2087-94.

36. Palareti G, Legnani C, Guazzaloca G, Lelia V, Cosmi B, Lunghi B, et al. Risks factors for highly unstable response to oral anticoagulation: a case-control study. British journal of haematology. 2005;129(1):72-8.

37. Garcia D, Regan S, Crowther M, Hughes RA, Hylek EM. Warfarin maintenance dosing patterns in clinical practice: implications for safer anticoagulation in the elderly population. Chest Journal. 2005;127(6):2049-56.

38. Jonas DE, McLeod HL. Genetic and clinical factors relating to warfarin dosing. Trends in pharmacological sciences. 2009;30(7):375-86.

39. Dang M-TN, Hambleton J, Kayser SR. The influence of ethnicity on warfarin dosage requirement. Annals of Pharmacotherapy. 2005;39(6):1008-12.

40. Yang F, Hellyer JA, Than C, Ullal AJ, Kaiser DW, Heidenreich PA, et al. Warfarin utilisation and anticoagulation control in patients with atrial fibrillation and chronic kidney disease. Heart.

2016:heartjnl-2016-309266.

41. Szummer K, Gasparini A, Eliasson S, Ärnlöv J, Qureshi AR, Bárány P, et al. Time in therapeutic range and outcomes after warfarin initiation in newly diagnosed atrial fibrillation patients with renal dysfunction. Journal of the American Heart Association. 2017;6(3):e004925.

42. Proietti M, Lane DA, Lip GY. Chronic kidney disease, time in therapeutic range and adverse clinical outcomes in anticoagulated patients with non-valvular atrial fibrillation: observations from the SPORTIF trials. EBioMedicine. 2016;8:309-16.

43. Kleinow ME, Garwood CL, Clemente JL, Whittaker P. Effect of chronic kidney disease on warfarin management in a pharmacist-managed anticoagulation clinic. Journal of Managed Care Pharmacy. 2011;17(7):523-30.

44. Dreisbach AW, Lertora JJ. The effect of chronic renal failure on drug metabolism and transport. Expert opinion on drug metabolism \& toxicology. 2008;4(8):1065-74.

45. Pokorney SD, Simon DN, Thomas L, Fonarow GC, Kowey PR, Chang P, et al. Patients' time in therapeutic range on warfarin among US patients with atrial fibrillation: Results from ORBIT-AF registry. American heart journal. 2015;170(1):141-8. e1.

46. Putnam A, Gu X, Haymart B, Kline-Rogers E, Almany S, Kozlowski J, et al. The changing characteristics of atrial fibrillation patients treated with warfarin. Journal of thrombosis and thrombolysis. 2015;40(4):488-93.

47. Gallagher AM, Setakis E, Plumb JM, Clemens A, van Staa T-P. Risks of stroke and mortality associated with suboptimal anticoagulation in atrial fibrillation patients. Thrombosis and haemostasis. 2011;106(5):968.

48. Mueller S, Pfannkuche M, Breithardt G, Bauersachs R, Maywald U, Kohlmann T, et al. The quality of oral anticoagulation in general practice in patients with atrial fibrillation. European journal of internal medicine. 2014;25(3):247-54.

49. Wieloch M, Själander A, Frykman V, Rosenqvist M, Eriksson N, Svensson PJ. Anticoagulation control in Sweden: reports of time in therapeutic range, major bleeding, and thrombo-embolic complications from the national quality registry AuriculA. European heart journal. 2011;32(18):22829.

50. Dlott JS, George RA, Huang X, Odeh M, Kaufman HW, Ansell J, et al. A national assessment of warfarin anticoagulation therapy for stroke prevention in atrial fibrillation. Circulation. 2014:113.002601.

51. Apostolakis S, Sullivan RM, Olshansky B, Lip GY. Factors affecting quality of anticoagulation control among patients with atrial fibrillation on warfarin: the SAMe-TT2R2 score. CHEST Journal. 2013;144(5):1555-63.

52. Lip GY, Waldo AL, Ip J, Martin DT, Bersohn MM, Choucair WK, et al. Determinants of Time in Therapeutic Range in Patients Receiving Oral Anticoagulants (A Substudy of IMPACT). The American Journal of Cardiology. 2016;118(11):1680-4. 
53. Rikala M, Hauta-Aho M, Helin-Salmivaara A, Lassila R, Korhonen MJ, Huupponen R. CoPrescribing of Potentially Interacting Drugs during Warfarin Therapy-A Population-Based Register Study. Basic \& clinical pharmacology \& toxicology. 2015;117(2):126-32.

54. Guo Y-t, Zhang Y, Shi X-m, Shan Z-I, Wang C-j, Wang Y-t, et al. Assessing bleeding risk in 4824 Asian patients with atrial fibrillation: The Beijing PLA Hospital Atrial Fibrillation Project. Scientific reports. 2016;6.

55. Barta AL, Nutescu EA, Thompson PA, Bussey HI, Gulseth MP. Relationship between time spent at extreme International Normalized Ratios and time in therapeutic range with bleeding and thrombosis in warfarin-treated patients. American Journal of Health-System Pharmacy. 2015;72(14). 56. Senoo K, Lane D, Lip GY. Stroke and bleeding risk in atrial fibrillation. Korean circulation journal. 2014;44(5):281-90.

57. Rouaud A, Hanon O, Boureau A-S, Chapelet GG, de Decker L. Comorbidities against Quality Control of VKA Therapy in Non-Valvular Atrial Fibrillation: A French National Cross-Sectional Study. PloS one. 2015;10(3):e0119043.

58. Razouki Z, Ozonoff A, Zhao S, Jasuja GK, Rose AJ. Improving Quality Measurement for Anticoagulation Adding International Normalized Ratio Variability to Percent Time in Therapeutic Range. Circulation: Cardiovascular Quality and Outcomes. 2014;7(5):664-9.

59. Wan Y, Heneghan C, Perera R, Roberts N, Hollowell J, Glasziou P, et al. Anticoagulation control and prediction of adverse events in patients with atrial fibrillation a systematic review. Circulation: Cardiovascular Quality and Outcomes. 2008;1(2):84-91.

60. Shehab A, Elnour AA, Bhagavathula AS, Erkekoglu P, Hamad F, AI Nuaimi S, et al. Novel oral anticoagulants and the 73rd anniversary of historical warfarin. Journal of the Saudi Heart Association. 2016;28(1):31-45.

61. Cryder B, Felczak M, Janociak J, Pena LD, Allen S, Gutierrez P. Prevalent aetiologies of nontherapeutic warfarin anticoagulation in a network of pharmacist-managed anticoagulation clinics. Journal of clinical pharmacy and therapeutics. 2011;36(1):64-70.

62. Harder S, Graff J. Novel oral anticoagulants: clinical pharmacology, indications and practical considerations. European journal of clinical pharmacology. 2013;69(9):1617-33. 


\section{TABLES AND FIGURES}

Table 1 - Patient demographics at the study sites in Australia and Singapore. Data shown is number and percentage. Mean and standard deviation is also shown for age, and median and interquartile range for risk scores.

\begin{tabular}{|c|c|c|}
\hline & Australia $(n=3196)$ & Singapore $(n=1170)$ \\
\hline \multicolumn{3}{|l|}{ Gender } \\
\hline Male & $1671(52.3 \%)$ & 706 (60.3\%) \\
\hline Female & 1525 (47.7\%) & $464(39.7 \%)$ \\
\hline Age - mean (SD) & $77.2(9.1)$ & $69.7(10.0)$ \\
\hline Age $<60$ years & $138(4.3 \%)$ & $176(15.0 \%)$ \\
\hline Age $60-69$ years & $458(14.3 \%)$ & $370(31.6 \%)$ \\
\hline Age $70-79$ years & 1185 (37.1\%) & 437 (37.4\%) \\
\hline Age $\geq 80$ years & $1415(44.3 \%)$ & $187(16.0 \%)$ \\
\hline \multicolumn{3}{|l|}{ Past Medical History } \\
\hline Hypertension & $1184(37.0 \%)$ & 697 (59.6\%) \\
\hline Diabetes & $562(17.6 \%)$ & $351(30.0 \%)$ \\
\hline Heart Failure & $278(8.7 \%)$ & $88(7.5 \%)$ \\
\hline Vascular Disease & 357 (11.2\%) & $279(23.8 \%)$ \\
\hline Chronic Kidney Disease & $149(4.7 \%)$ & $163(13.9 \%)$ \\
\hline Abnormal liver function & $11(0.3 \%)$ & $6(0.5 \%)$ \\
\hline History of stroke or TIA & $487(15.2 \%)$ & $46(3.9 \%)$ \\
\hline History of bleeds & $18(0.6 \%)$ & $0(0 \%)$ \\
\hline History of cancer & $277(8.7 \%)$ & $423.6 \%)$ \\
\hline Anaemia & $50(1.6 \%)$ & $64(5.5 \%)$ \\
\hline Cardiomyopathy & $136(4.3 \%)$ & $107(9.1 \%)$ \\
\hline Dyslipidaemia & $470(14.7 \%)$ & 607 (51.9\%) \\
\hline \multicolumn{3}{|l|}{ Risk Model Scores } \\
\hline $\mathrm{CHA}_{2} \mathrm{DS}_{2}$-VASc score 0 & $101(3.2 \%)$ & $93(7.9 \%)$ \\
\hline $\mathrm{CHA}_{2} \mathrm{DS}_{2}$-VASc score 1 & $374(11.7 \%)$ & $170(14.5 \%)$ \\
\hline $\mathrm{CHA}_{2} \mathrm{DS}_{2}$-VASc score 2 & $717(22.4 \%)$ & $266(22.7 \%)$ \\
\hline $\mathrm{CHA}_{2} \mathrm{DS}_{2}$-VASc score 3 & $869(27.2 \%)$ & $294(25.2 \%)$ \\
\hline $\mathrm{CHA}_{2} \mathrm{DS}_{2}$-VASc score 4 & $581(18.2 \%)$ & $197(16.8 \%)$ \\
\hline $\mathrm{CHA}_{2} \mathrm{DS}_{2}$-VASc score 5 & $346(10.8 \%)$ & $106(9.1 \%)$ \\
\hline $\mathrm{CHA}_{2} \mathrm{DS}_{2}$-VASc score 6 & $165(5.1 \%)$ & $35(3.0 \%)$ \\
\hline $\mathrm{CHA}_{2} \mathrm{DS}_{2}$-VASc score 7 & $35(1.1 \%)$ & $9(0.8 \%)$ \\
\hline $\mathrm{CHA}_{2} \mathrm{DS}_{2}$-VASc score 8 & $8(0.3 \%)$ & \\
\hline $\begin{array}{l}\mathrm{CHA}_{2} \mathrm{DS}_{2}-\mathrm{VASc} \text { score, } \\
\text { median (IQR) }\end{array}$ & $3(0-8)$ & $3(0-7)$ \\
\hline $\begin{array}{l}\text { HAS-BLED score, } \\
\text { median (IQR) }\end{array}$ & $1(0-5)$ & $1(0-4)$ \\
\hline \multicolumn{3}{|l|}{ Concurrent treatment } \\
\hline Amiodarone & $215(6.7 \%)$ & $76(6.5 \%)$ \\
\hline Beta-blockers & 1995 (62.4\%) & $912(77.9 \%)$ \\
\hline Amiodarone \& Betablocker & $117(3.7 \%)$ & $54(4.6 \%)$ \\
\hline Digoxin & $1082(33.9 \%)$ & $331(28.3 \%)$ \\
\hline $\begin{array}{l}\text { Angiotensin Converting Enzyme } \\
\text { Inhibitor }\end{array}$ & $1116(34.9 \%)$ & $338(28.9 \%)$ \\
\hline Angioreceptor Blocker & $887(27.7 \%)$ & $320(27.4 \%)$ \\
\hline
\end{tabular}




\begin{tabular}{|l|l|l|}
\hline Calcium channel blocker & $823(25.8 \%)$ & $386(33.0 \%)$ \\
\hline Statin & $1765(55.2 \%)$ & $852(72.8 \%)$ \\
\hline Platelet Inhibitor & $287(9.0 \%)$ & $300(25.6 \%)$ \\
\hline Diuretic & $1291(40.4 \%)$ & $420(35.9 \%)$ \\
\hline Proton Pump Inhibitor & $1163(36.4 \%)$ & $520(44.4 \%)$ \\
\hline
\end{tabular}

Table 2 - Warfarin control at the study sites in Australia and Singapore. Data shown is mean (standard deviation) for warfarin control with median (interquartile range) shown for warfarin dose information.

\begin{tabular}{|l|l|l|l|}
\hline & Australia & Singapore & P Value \\
\hline Warfarin Control & & & \\
\hline Total number of tests & 35898 & 6588 & \\
\hline Time in therapeutic range & $82.4(15.6)$ & $57.6(34.2)$ & $\mathrm{P}<0.0001$ \\
\hline Percentage tests in range & $78.9(19.1)$ & $54.2(30.5)$ & $\mathrm{P}<0.0001$ \\
\hline Frequency of testing & $16.9(8.1)$ & $29.3(15.2)$ & $\mathrm{P}<0.0001$ \\
\hline Weekly warfarin dose & $26.2(12.0)$ & $18.4(8.3)$ & $\mathrm{P}<0.0001$ \\
\hline $\begin{array}{l}\text { Weekly warfarin dose } \\
\text { median (IQR) }\end{array}$ & $24.3(3.5-94.5)$ & $16.5(3.5-63)$ & $\mathrm{P}<0.0001$ \\
\hline Number of dose changes & $2.5(2.7)$ & $1.0(1.5)$ & $\mathrm{P}<0.0001$ \\
\hline $\begin{array}{l}\text { Number of dose changes } \\
\text { median (IQR) }\end{array}$ & $2(0-18)$ & $0(0-9)$ & $\mathrm{P}<0.0001$ \\
\hline
\end{tabular}


Table 3 - Warfarin control at the study sites in Australia and Singapore according to time in therapeutic range (TTR) both above and below 65\%. Data shown is mean (standard deviation) for warfarin control with median (interquartile range) also shown for warfarin dose information.

\begin{tabular}{|l|l|l|l|l|l|l|}
\hline & \multicolumn{3}{|l|}{ Australia $(\mathbf{n}=\mathbf{3 1 9 6})$} & \multicolumn{3}{l|}{ Singapore (n=1170) } \\
\hline & TTR<65\% & TTR $>65 \%$ & P value & TTR<65\% & TTR>65\% & P value \\
\hline Total & $\begin{array}{l}446 \\
(14.0 \%)\end{array}$ & $\begin{array}{l}2750 \\
(86.0 \%)\end{array}$ & & $\begin{array}{l}627 \\
(53.6 \%)\end{array}$ & $\begin{array}{l}543 \\
(46.4 \%)\end{array}$ & \\
\hline Male & $\begin{array}{l}245 \\
(54.9 \%)\end{array}$ & $\begin{array}{l}1426 \\
(51.8 \%)\end{array}$ & & $\begin{array}{l}366 \\
(58.4 \%)\end{array}$ & $\begin{array}{l}340 \\
(62.6 \%)\end{array}$ & \\
\hline Female & $\begin{array}{l}201 \\
(45.1 \%)\end{array}$ & $\begin{array}{l}1324 \\
(48.1 \%)\end{array}$ & & $\begin{array}{l}261 \\
(41.6 \%)\end{array}$ & $\begin{array}{l}203 \\
(37.4 \%)\end{array}$ & \\
\hline Age & $75.9(10.3)$ & $77.4(8.9)$ & $\mathrm{P}=0.0154$ & $69.9(9.9)$ & $69.4(10.2)$ & \\
\hline $\begin{array}{l}\text { Warfarin } \\
\text { Control }\end{array}$ & & & & & & \\
\hline $\begin{array}{l}\text { Total number of } \\
\text { tests }\end{array}$ & 7202 & 28696 & & 4431 & 2157 & \\
\hline $\begin{array}{l}\text { Percentage tests } \\
\text { in range }\end{array}$ & $54.3(11.9)$ & $82.9(17.0)$ & $\mathrm{P}<0.0001$ & $34.5(19.7)$ & $76.9(24.2)$ & $\mathrm{P}<0.0001$ \\
\hline $\begin{array}{l}\text { Frequency of } \\
\text { testing }\end{array}$ & $11.3(4.7)$ & $17.8(8.2)$ & $\mathrm{P}<0.0001$ & $24.1(14.5)$ & $35.2(13.8)$ & $\mathrm{P}<0.0001$ \\
\hline $\begin{array}{l}\text { Weekly warfarin } \\
\text { dose }\end{array}$ & $26.4(13.3)$ & $26.2(11.8)$ & & $18.4(8.6)$ & $18.4(7.9)$ & \\
\hline $\begin{array}{l}\text { Weekly warfarin } \\
\text { dose } \\
\text { median (IQR) }\end{array}$ & $23.9(3.5-$ & $24.5(4.5-$ & & $\begin{array}{l}16.8(3.5- \\
63)\end{array}$ & $\begin{array}{l}16.5(5.5- \\
61.5)\end{array}$ & \\
\hline $\begin{array}{l}\text { Number of dose } \\
\text { changes }\end{array}$ & $6.4(3.4)$ & $1.9(2.0)$ & $\mathrm{P}<0.0001$ & $1.6(1.7)$ & $0.4(0.7)$ & $\mathrm{P}<0.0001$ \\
\hline $\begin{array}{l}\text { Number of dose } \\
\text { changes median } \\
\text { (IQR) }\end{array}$ & $6(0-18)$ & $1(0-10)$ & & $1(0-9)$ & $0(0-5)$ & \\
\hline
\end{tabular}


A USTRALIA

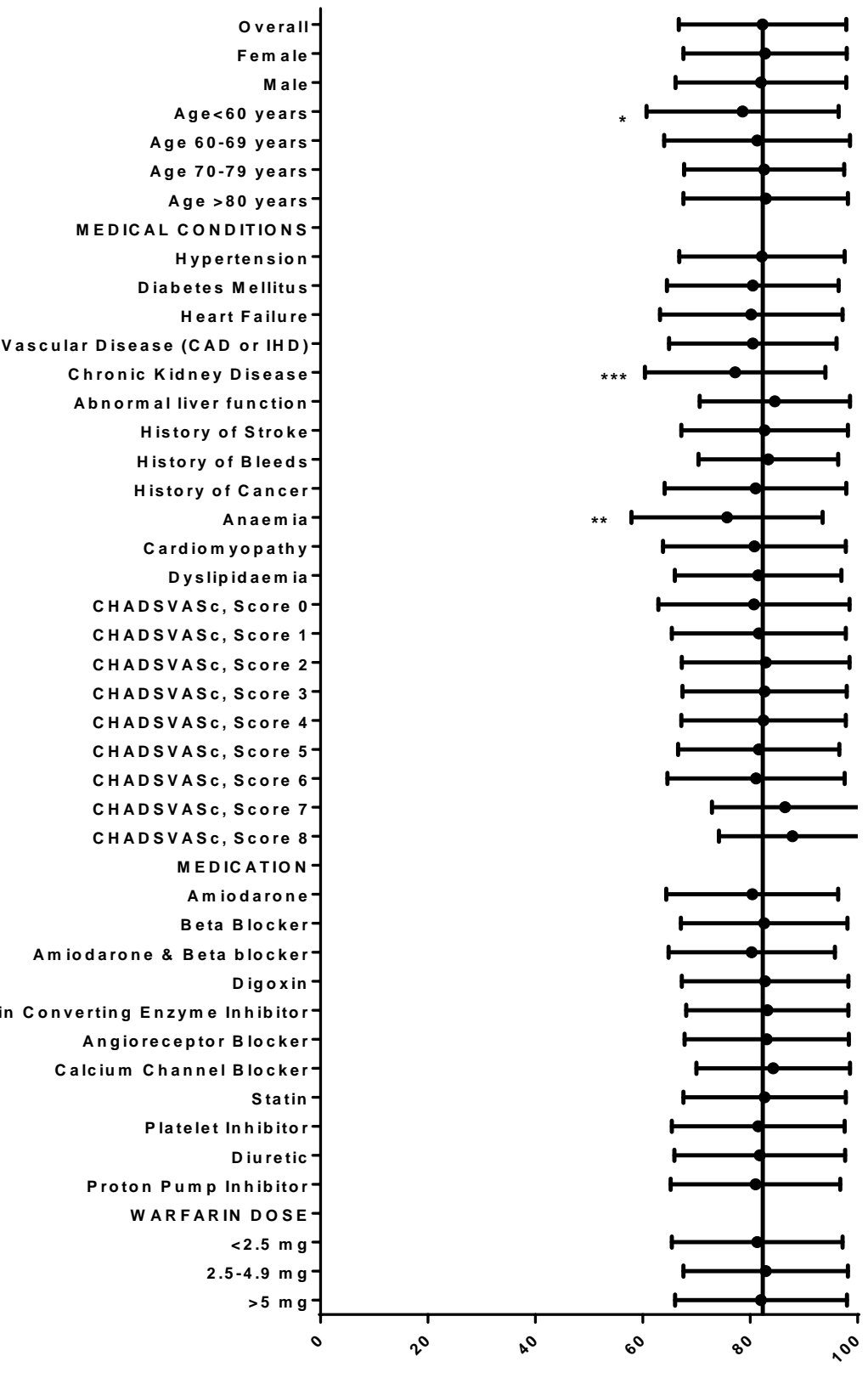

SINGAPORE

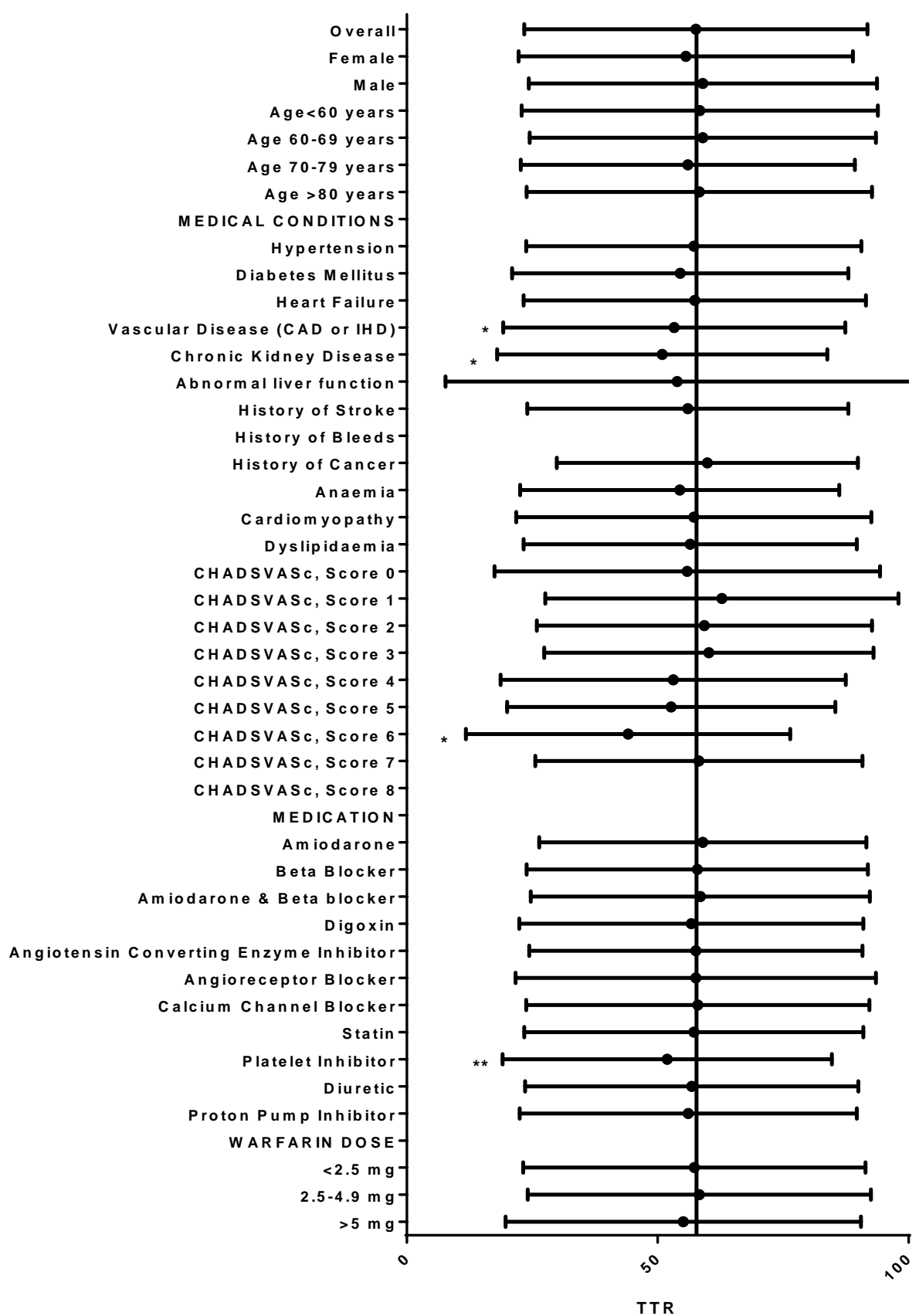


Figure 1 - Comparison of mean TTR in Australia and Singapore to demographic and clinical characteristics. Individual data plotted represents mean and standard deviation with the solid vertical line representing the mean TTR at the site. Significance is represented as ${ }^{*} p<0.05, * * p<0.01$, and ${ }^{* * *} p<0.001$ 